\title{
Professionalism Kills the Trading Star: Explaining Member Participation in Trading Com- munities
}

By Sabine Benoit*, Jens Hogreve, Christina Sichtmann and Nicola Bilstein

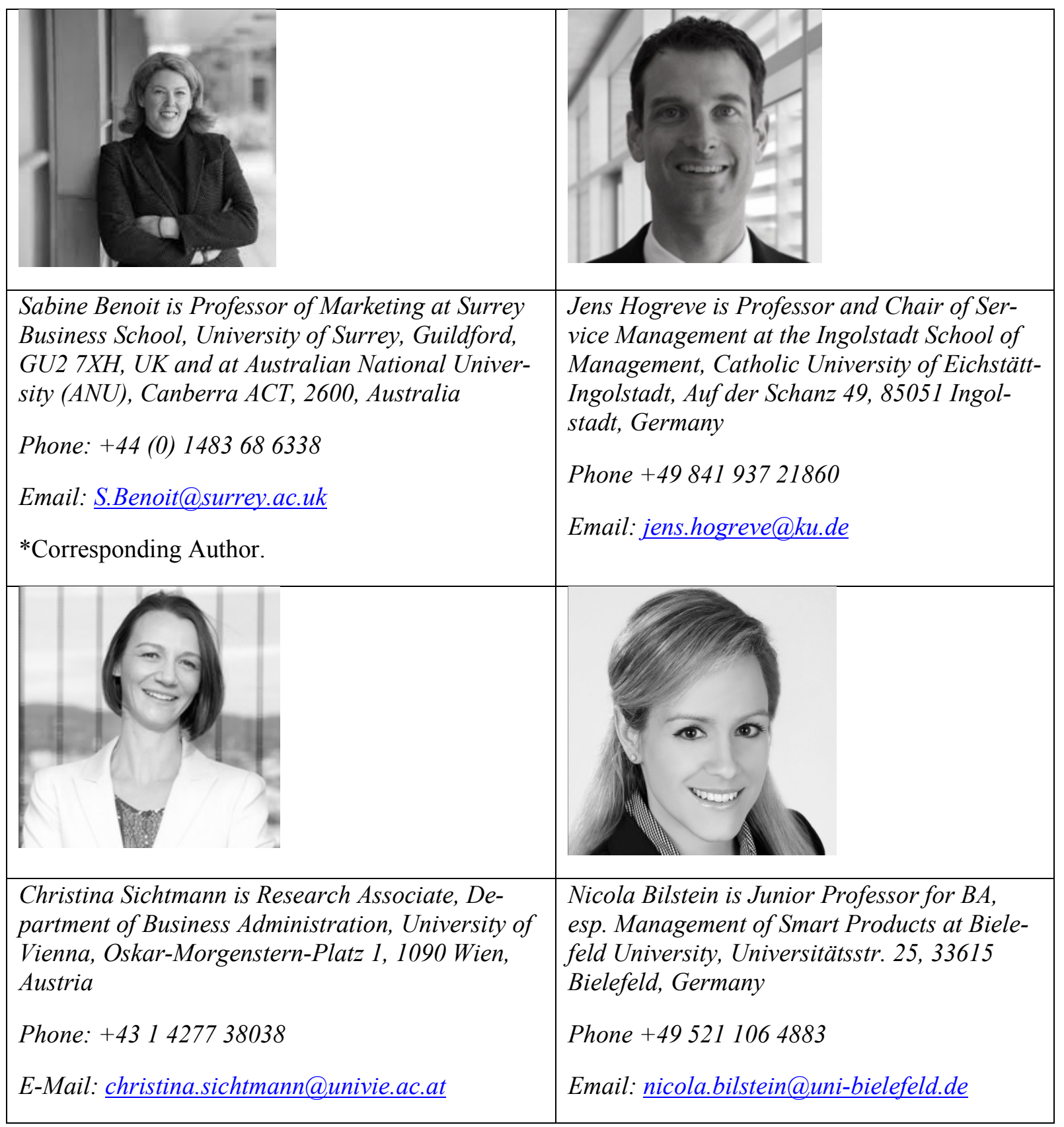

Acknowledgments:

The authors thank the cooperation partner who gave access to the data, that preferred to remain anonymous and Adamantios Diamantopoulos for his valuable comments on former versions of this manuscript. 


\title{
Professionalism Kills the Trading Star: Explaining Member Participation in Trading Communities
}

\begin{abstract}
Trading communities provide non-commercial members with an online platform on which to exchange goods. Its success depends on member participation; however, little is known about its drivers. Based on literature we identify five drivers. To capture their impact over time, we test a latent growth curve model with longitudinal data, comparing the effects at an initial point of time with their impact on the growth of member participation over three subsequent periods. The results show that providers' responsiveness and community identification have a positive effect on the initial level, but not on growth. Members' enjoyment has no level effect, but a growth effect. Only role clarity has an impact on level and growth. Interestingly, co-members' cooperation weakens member participation, which leads us to conclude that too much cooperation - which appears as professionalism in a trading community - 'kills' member participation. We conclude with theoretical and managerial implications.
\end{abstract}

Keywords: member participation, sharing communities, collaborative consumption, online communities, latent growth curve modelling 


\section{Introduction}

Trading communities such as Gametz (game trading), BookMooch (book trading), and Totspot (trading of children's clothes) give non-commercial members an online platform to trade their goods with other members and thus exchange them within the community. This contrasts with many communities of interest that focus on connecting their members around a certain topic, e.g. diabetes.co.uk/forum (de Valck et al. 2007) or information-based communities such as Facebook that focus on cultivating relationships through the exchange of information (Wiertz and de Ruyter 2007). Trading communities enable the exchange of products among their members and thus allow collaborative consumption (Benoit et al. 2017; Hamari et al. 2016). They can also be specified as two-sided networks (Parker and Van Alstyne 2005). As such, they are a research priority for service research because they represent networks and are part of the sharing economy (Benkenstein et al. 2017).

Trading communities play an important role in modern economies and are of a triadic nature; this is similar to many service business models in the sharing economy involving a platform or community provider that connects a peer service provider to a customer (Benoit et al. 2017). A recent study found that around half of the online communities that allow sharing and collaborative consumption enable temporal access to goods of peer service providers without ownership transfer (e.g. giving access, renting, and borrowing), while the other half involves some ownership transfer (e.g. donating, swapping, and trading) (Hamari et al. 2016).

A key element within a trading community is delivered by the community members themselves (Kozinets et al. 2010), revealing the increasingly important role that customers play in value creation beyond firm boundaries (Frow et al. 2015). The community provider's role is to enable and encourage trading by managing the community (Benoit et al. 2017). Members usually 
pay a transaction fee to the provider for this service (Zeng and Glaister 2016). Consequently, in many cases, the income of a community provider depends on the volume of trades within the community - the latter defined as 'member participation' in this research.

Despite the importance of member participation in the financial success and survival of trading communities (Cho and Menor 2010; Tsai and Bagozzi 2014), little research exists into what drives participation in this context (Hamari et al. 2016; Sichtmann et al. 2011). We build on our prior research on participation in online communities (i.e. Benoit et al. 2016; Sichtmann et al. 2011) and expand this research in two important ways: first, by investigating the drivers of participation operationalizing it with transaction data; and second, by relying on longitudinal data as opposed to cross-sectional data to track the influence of drivers on participation over a period of time. We begin by identifying the effect of the drivers on the level of member participation at the beginning of the observation period (initial level), and then assess whether these drivers increase participation over time (growth). To date, empirical research has not yet separated these effects. Our results clearly indicate that it is important to do so.

Our study thus offers several substantive contributions. First, based on online community, participation, and collaborative consumption literature, we identify and validate significant drivers of member participation in trading communities that relate to three important stakeholder groups: the focal member, co-members, and the community provider (Benoit et al. 2016; Benoit et al. 2017; de Valck et al. 2007). In this vein, we contribute to these streams of literature by providing further empirical validation for drivers of participation behaviour in a triadic, membership-based service setting.

Second, we document the immediate effects not only on the initial level of participation, but also on the growth of participation over time. More specifically, we combine survey data with 
information gathered from a provider about longitudinal transactions, using latent growth curve modelling to analyse this data. Our results show that some drivers affect only the initial level, but not growth; contrariwise, others only affect either growth or both the initial level and growth.

Third, by measuring member participation in terms of trades that directly link to the provider's income, we are able to prioritize the financial impact of various drivers for providers over time. This approach also responds to calls to use financial metrics in marketing research when assessing the financial performance of online business models (Köhler et al. 2011).

Fourth, from an empirical perspective, our study contributes to the measurement of participation behaviour by operationalizing it with actual behavioural data. Our research combines survey data from community members with transaction data about their actual participation behaviour. This is recommended in the literature (Matzner et al. 2018) and is important since prior research has measured it primarily through self-reported survey data (see Chan et al. 2010; Gallan et al. 2013; Hamari et al. 2016; Troye and Supphellen 2012; Wiertz and de Ruyter 2007).

By consolidating these four contributions, we present managerial guidance on how best to manage trading communities. By identifying and prioritizing the drivers of member participation, we offer insights into how trading community providers might leverage their income. To do so, the article progresses as follows. First, we define and describe our service context, which is trading communities. Next, we lay the theoretical foundation for our research in social exchange theory and deduce our hypotheses from the theory and literature on customer participation, online communities, and collaborative consumption. The subsequent section presents our empirical approach to test our hypothesis and the findings that are discussed in 
section five. Lastly, we present theoretical contributions, managerial implications, and limitations.

\section{Theoretical Foundation and Model Overview}

Trading communities are defined as peer-to-peer online platforms for non-commercial members to offer goods to other non-commercial members; these exchanges are enabled by the community provider. Prior literature refers to trading communities as part of collaborative consumption involving obtaining or giving access to goods of peers as coordinated by community-based online services (Benoit et al. 2017; Hamari et al. 2016). Trading communities not only connect members (i.e. information exchange) but also initiate a form of commerce (i.e. trading) among non-commercial members (Bakos and Katsamakas 2008). The community provider's main role is to enable those trades among members by managing the online community (Hamari et al. 2016; Sichtmann et al. 2011). Many trading communities charge a transaction or trade fee payable to the provider (Zeng and Glaister 2016). The business model of trading communities thus relies on member participation (Cho and Menor 2010; Tsai and Bagozzi 2014), with the income generator being the transaction fee (Zeng and Glaister 2016).

We expand our initial work on trading communities (Sichtmann et al. 2011) by using longitudinal transaction data, which allows us to focus on behavioural changes in participation that these drivers entail over time. To capture participation and its economic relevance, we need to differentiate: 1) the actual trade (an offer matching a demand); 2) activities that prepare a particular trade (e.g. describing the product or service, and answering questions about the product or service); and 3) activities that are not related to a particular trade but rather to being a member of the community (e.g. setting up a profile, evaluating co-members, and writing reviews). In general, only the first type of activity is income-generating for the community 
provider, because the provider usually charges a trading fee. Type 2 and 3 are secondary activities that might lead to trades (type 1). Our dependent variable is operationalized in a way to capture the 'income-generating member participation' and thus only includes type 1 activities that equal successful trades. Because of this operationalization, we can make statements relating to the financial value of the drivers.

Our research model on the drivers of member participation in trading communities (depicted in Fig. 1) was inspired by earlier work (Sichtmann et al. 2011) and is based on social exchange theory as well as literature streams of customer participation, online communities, and collaborative consumption. Following Bagozzi (1979, pp. 434), an exchange in marketing encompasses "a transfer of something tangible or intangible, actual or symbolic between two or more social actors". Social exchange theory (Blau 1964; Homans 1966) applies to trading communities since trades constitute exchanges among community members (Faraj and Johnsons 2010). Hereby, exchange partners evaluate the outcomes of an exchange that may be composed of social (e.g. approval, status, discrimination, and ostracism) and/or economic elements (e.g. monetary gains or losses) (Bagozzi 1978). Exchange partners only remain in the exchange relation if their rewards exceed the costs (Blau 1964; Homans 1966), since only then do they derive value from the exchange relation.

In line with social exchange theory and prior literature on participation, we identify drivers that affect focal members' costs and rewards in trading communities and thus influence the level of participation. To account for the triadic structure of actors in trading communities (Benoit et al. 2017), our model is inspired by our prior work on participation in informationbased online communities and thus considers both intra- and interpersonal influences (Benoit et al. 2016). Our model includes focal member characteristics (enjoyment, role clarity, and 
community identification) to represent the intrapersonal influences. Co-members' cooperation and provider responsiveness represent the interpersonal influences.

Because enjoyment has been identified as a major relevant driver for participation in technology-based self-service (Dabholkar and Bagozzi 2002), online communities (Venkatesh et al. 2002), and the sharing economy (Hamari et al. 2016), we include it in our study to investigate its impact in trading communities. To further capture the member-specific drivers, we investigate the effect of member role clarity, i.e. the sense of having the required "knowledge and understanding of what to do" in a service setting (Meuter et al. 2005, pp. 64), since it has shown to be very relevant in dyadic customer participation situations (Auh et al. 2007; Guo et al. 2013). The third variable that has been included to capture member influence in trading communities is community identification, because it has shown to be a relevant construct particularly for exchanges in brand communities (e.g. Algesheimer et al. 2005; Bagozzi and Dholakia 2006).

The main 'contract partner' in a trade is the co-member since the provider only enables the trades through the platform and acts as a matchmaker (Benoit et al. 2017; Hamari et al. 2016; Sichtmann et al. 2011). The focal member himself/herself is thus dependent on co-members to behave fairly, answer queries, and be flexible, which we capture in our research by including comembers' cooperation in the trading community.

The community provider supplies the technical interface (Benoit et al. 2017). Within the community, they set and monitor rules for trades (Porter and Donthu 2008) and coordinate the trades (Hamari et al. 2016), which has been called 'matchmaking' (Benoit et al. 2017). Thus, the main personal point of contact between the provider and the member will be irregular service situations in which the provider needs to respond to members' problems or concerns. We capture 
this influencing factor on participation by including the perception of provider responsiveness in our model.

Fig. 1 depicts the research model of the study. On the left side, it shows the specific drivers investigated based on social exchange theory and participation literature. The right side of the research model implies that we expect the drivers to not only have an instant effect on the initial income-generating participation level, but also - over time - affect its growth.

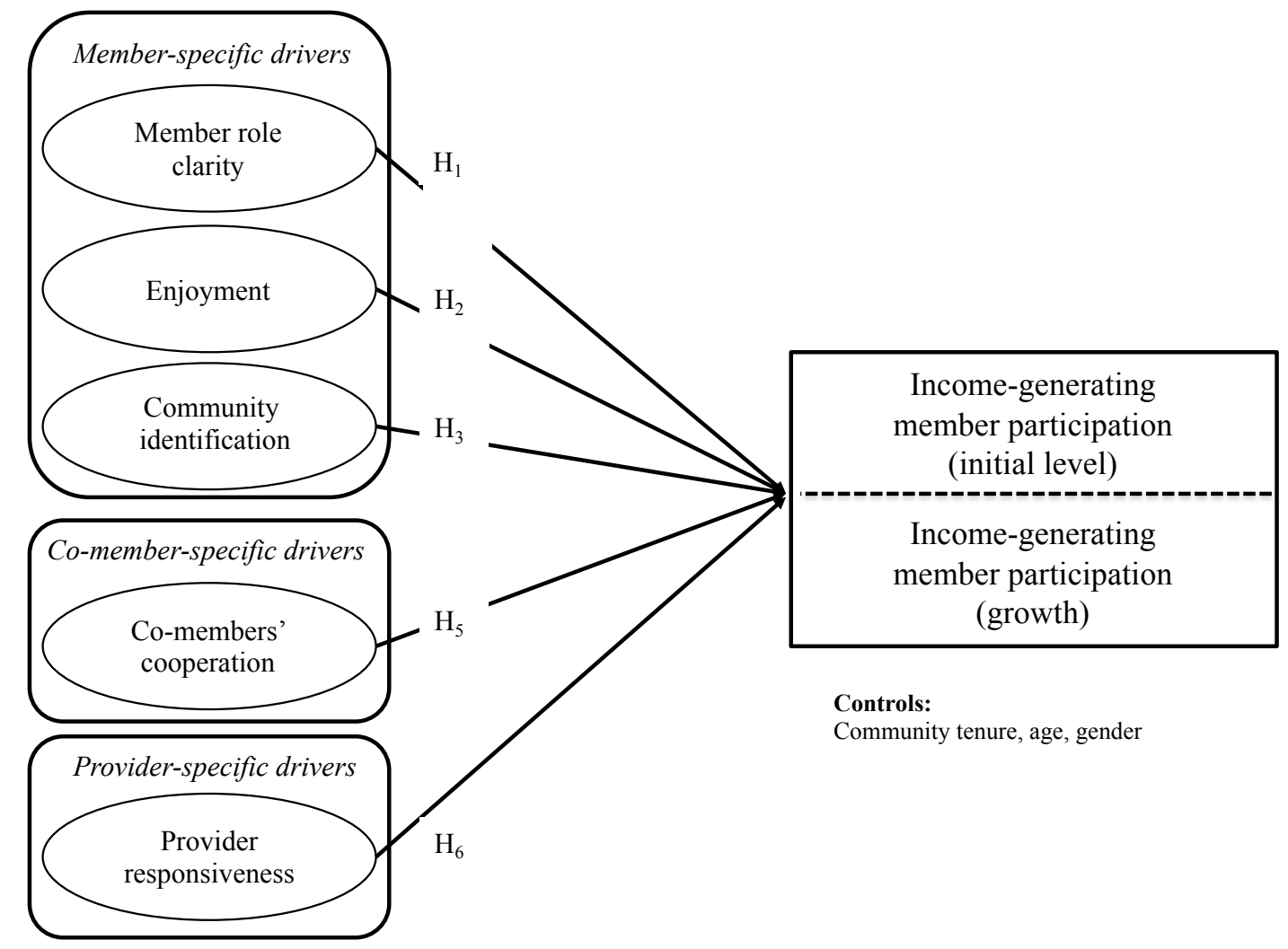

Fig. 1: The Research Model

\section{Hypotheses}

\subsection{Member-Specific Driver: Enjoyment}

Enjoyment is defined as the degree to which the participation in a trading community "is perceived to provide reinforcement in its own right, apart from any performance consequences 
that may be anticipated" (Childers et al. 2001, pp. 513). Enjoyment has shown to be a driver of participation in online communities (Benoit et al. 2016; Hamari et al. 2016; Venkatesh et al. 2002), as well as in other online contexts such as technology-based self-service (Dabholkar and Bagozzi 2002). In line with social exchange theory, enjoyment ameliorates the rewards connected to participation and reduces its perceived costs. Moreover, enjoyment should have a lasting effect on participation. Füller et al. (2009/10) suggest that people who enjoy a specific task have a higher tendency to repeat it. In a new product development context, these authors reveal that experiencing enjoyment is a key antecedent of intentions of future participation. Because enjoyment should affect not only current participation behaviours but also the likelihood of future participation, we predict that members who enjoy participating in the trading community exhibit both a higher initial level and a stronger positive growth rate of member participation over time:

$H_{1}$ : Members' enjoyment will have positive effects on (a) the initial level and (b) the growth rate of income-generating member participation within the trading community.

\subsection{Member-Specific Driver: Role Clarity}

Customer participation literature emphasizes the importance of role clarity, defined as "consumer's knowledge and understanding of what to do" in a service setting (Meuter et al. 2005 , pp. 64). In a trading community, role clarity specifically refers to the members' understanding of the tasks and functions that they need to accomplish as well as to the knowledge of the rules in a trading community. Role clarity is an important prerequisite for customer participation and implies a specific investment of the member in terms of time and effort sacrificed to participate (Lengnick-Hall 1996). In line with social exchange theory, higher role clarity should lead to lower perceived costs of participation in a trading community, as 
members with more role clarity are more aware of their responsibilities and expected behaviours (Guo et al. 2013). Therefore, they likely feel comfortable in the online community immediately, such that they acclimatize more quickly and interact with other community members more easily. Similarly, Gallan et al. (2013) reveal that customer positivity (i.e. situation-specific positive affectivity) predicts participation behaviours. Not only do members with strong role clarity reveal a higher initial level of participation, but they also can coproduce more effective outcomes, which makes them more loyal to the community (Auh et al. 2007) and more likely to increase their participation over time. Thus, we hypothesize:

$H_{2}:$ Members' role clarity will have positive effects on (a) the initial level and (b) the growth rate of income-generating member participation within the trading community.

\subsection{Member-Specific Drivers: Community Identification}

The idea that members have different levels of identification with their communities has been taken from online community literature, which defines it as the strength of the user's relationship with an online community - also represented by a sense of belonging (Algesheimer et al. 2005). Community identification is seen as a reward since it is linked with social recognition, common consumption values, and interest (Scarpi 2010). Thus, in line with social exchange theory, it should constitute a benefit and thus drive participation. Prior research confirms this by revealing that social benefits (Dholakia et al. 2009), identification with the community (Bagozzi and Dholakia 2006), and we-intentions (Dholakia et al. 2004; Tsai and Bagozzi 2014) are important drivers of member participation. Along these lines, we expect that community identification will predict not only the initial level of participation, but also its growth over time. Thus, we conclude: 
H3: Community identification will have positive effects on (a) the initial level and (b) the growth rate of income-generating member participation within the trading community.

\subsection{Co-Member-Specific Drivers: Co-Member Cooperation}

The focal member gets into contact with co-members when trading, and in this way is exposed to different levels of co-member cooperation (Dong et al. 2006), defined as behaviour that is characterized by fairness, integrity, and justice (Auh et al. 2007; Ridings et al. 2006) which in a business and exchange context can be interpreted as a certain level of professionalism. Perceptions of co-members as cooperative should lead the member to anticipate more benefits (Arena and Conein 2008), whereas if members believe that co-members are not acting in accordance with the community guidelines and norms or contributing to the community, they are likely to fear greater costs associated with reduced service quality and quantity (Auh et al. 2007). Thus, in line with social exchange theory and online community literature - which has shown that cooperation influences a member's participation (Dong et al. 2006) - we predict that if members believe that co-members use and contribute to fair trades, they should reciprocate and be more likely to trade in the trading community (Arena and Conein 2008). If members experience balanced reciprocity for their own contributions to an online community from comembers' contributions and fair behaviour (Wang and Fesenmaier 2003), they should trust that the social exchange is working and engage in more future participation (Ridings et al. 2006; Wiertz and de Ruyter 2007). Thus, both the initial level of participation and its growth will be affected by co-member cooperation. Therefore, we propose:

H4: Co-members' cooperation will have positive effects on (a) the initial level and (b) the growth rate of income-generating member participation within the trading community.

\subsection{Provider-Specific Drivers: Provider Responsiveness}


In trading communities, the platform enables trading in which the co-member is the main interaction partner while the provider will likely remain in the background and engage in unusual situations (Porter and Donthu 2008; Rothaermel and Sugiyama 2001). The platform provider shapes and communicates the social norms and aligns the practices (Benoit et al. 2017). This means that in the event of divergence from these norms or disagreement between members, the provider's role is to be responsive to guarantee that all members can have beneficial relationships. Research on complaint handling has shown that provider behaviour is the 'acid test' for relationships and thus crucial in atypical situations (Homburg and Fürst 2005). In line with social exchange theory, such responsiveness should influence the perceived benefits and costs of member participation. With greater provider responsiveness, the control costs and perceived risk of a trade decrease, which again should make participation more likely and impact its initial level. Moreover, and in line with theories of exchange, we argue that when members feel more secure and trusting in an environment, they reciprocate by increasing their participation over time. Accordingly, we hypothesize:

$H_{5}$ : The provider's responsiveness will have positive effects on (a) the initial level and (b) the growth rate of income-generating member participation within the trading community.

\section{Analysis and Findings}

\subsection{Sample}

We collaborated with the provider of a major German trading community to collect the data. In this trading community, members trade (i.e. barter) media products for other products using a community currency (i.e. tokens). A typical transaction in this trading community proceeds as follows: A member offers a DVD for four tokens. If co-members want to trade this DVD, they 
must pay the price of four tokens, which they can obtain either by having traded their products beforehand or by purchasing tokens from the trading community provider. After the trade, each partner evaluates its quality.

We gathered data from two sources. ${ }^{1}$ First, to measure the drivers of member participation and demographics, we conducted a survey and obtained self-reported survey data from participants. We used personalized emails, sent to 3,620 randomly chosen community members, and lottery incentives worth $120 €$ in total. The 1,232 members who answered the questionnaire represented a response rate of 34\%. After excluding incomplete and inconsistent questionnaires as well as respondents who had not been active for at least three months - a commonly used criterion to distinguish active members from inactive members (Nonnecke et al. 2006) - we retained a sample of 933 respondents.

Second, we matched these respondents with objective data from the trading community provider via an individual member number. The provider delivered corresponding objective data for 760 respondents. At this stage, we determined the number of trades undertaken by each member. To analyse the dynamic nature of member participation and calculate the long-term effects of the drivers, we collected this objective data over a period of two consecutive years. To create sufficient variation in the data, we summed trades over nine months, such that our analysis covers three observation periods.

Our sample consisted of $61.1 \%$ men. In terms of age, $20.3 \%$ of respondents were younger than 29 years, $36.1 \%$ were between 30 and 39 years of age, $29.9 \%$ were between 40 and 49

\footnotetext{
${ }^{1}$ The cross-sectional survey data on the drivers of member participation stems from the same data set used in Sichtmann et al. (2011). For this research that focuses on behavioral changes, the survey data was matched with longitudinal transaction data from the trading community provider to measure income-generating member participation.
} 
years, $10.2 \%$ were between 50 and 59 years, and $3.6 \%$ were older than 60 years. The respondents stated that they had belonged to the trading community for $2-80$ months (mean $=21.31 ; \mathrm{SD}=$ 10.32) at the time of the survey.

\subsection{Measures}

To measure the constructs, we referred to existing scales and adapted them to the study context (all responses used seven-point, Likert-type scales, from $1=$ 'strongly disagree' to $7=$ 'strongly agree'; see $T a b .1$ ). For co-members' cooperation, we relied on the interactional justice scale by Auh et al. (2007) and a scale of integrity/benevolence by Ridings et al. (2006), modified to refer to co-members' behaviour rather than that of the service provider. As mentioned above, to measure member participation, we used transaction data from the provider and operationalized our dependent variable as income-generating member participation, i.e. participation activities for which a fee is charged in this trading community. Thus, the transaction data that we included in the dependent variable equalled transactions accomplished by members, i.e. member participation from the customer perspective, but also represent income from the provider perspective.

\begin{tabular}{|c|c|c|c|c|}
\hline Indicators & $\begin{array}{c}\text { Factor } \\
\text { Loadings }\end{array}$ & AVE & $\mathbf{C R}$ & Mean (SE) \\
\hline $\begin{array}{l}\text { Member's enjoyment (Venkatesh et al. 2002) } \\
\text { I find bartering via [name of community] to be enjoyable. } \\
\text { I felt very good about my last barters via [name]. } \\
\text { I have fun trading products via [name]. }\end{array}$ & $\begin{array}{l}.91 \\
.88 \\
.92\end{array}$ & .81 & .93 & $5.63(1.17)$ \\
\hline $\begin{array}{l}\text { Member's role clarity (Köhler et al. 2011; Meuter et al. 2005) } \\
\text { I am well informed about how barters via [name] work. } \\
\text { I have knowledge of the advantages and disadvantages of barters via } \\
\text { [name]. } \\
\text { I know what is expected of me if I use [name]. } \\
\text { I know all the rules and principles that have to be considered when settling } \\
\text { barters via [name]. }\end{array}$ & $\begin{array}{l}.88 \\
.83 \\
.93 \\
.84\end{array}$ & .76 & .93 & $6.24(.96)$ \\
\hline $\begin{array}{l}\text { Provider's responsiveness (Auh et al. 2007) } \\
\text { I can rely upon [name] to find a solution when there is a problem with a } \\
\text { barter. } \\
\text { [Name] takes seriously any concerns I have regarding barters. }\end{array}$ & $\begin{array}{l}.95 \\
.96\end{array}$ & .91 & .95 & $5.19(1.31)$ \\
\hline $\begin{array}{l}\text { Co-members' cooperation (Auh et al. 2007; Ridings et al. 2006) } \\
\text { My trading partners behave fairly in dealing with me. }\end{array}$ & .87 & .78 & .91 & $5.24(1.16)$ \\
\hline
\end{tabular}




\begin{tabular}{lccc}
\hline Indicators & $\begin{array}{c}\text { Factor } \\
\text { Loadings }\end{array}$ & AVE CR & Mean (SE) \\
\hline $\begin{array}{l}\text { My trading partners are usually quick in answering any questions I have } \\
\text { about the products that are being offered. }\end{array}$ & .91 & & \\
My trading partners are usually flexible when dealing with any concerns I & .87 & & \\
have. & & & \\
\hline Community identification (Algesheimer et al. 2005; Auh et al. 2007) & .82 & & \\
I feel like part of [name]. & .87 & & \\
[Name] has a great deal of personal meaning for me. & .86 & & \\
I feel emotionally attached to [name]. & .91 & & \\
I feel a sense of belonging to [name]. & & & \\
\hline
\end{tabular}

Notes: $\mathrm{AVE}=$ average variance extracted, $\mathrm{CR}=$ composite reliability, $\mathrm{SE}=$ standard deviation.

\section{Tab. 1: Reliability and Validity of Scales}

To assess measurement quality, we ran a confirmatory factor analysis with all constructs in our model by using Mplus 6.1 (Muthén and Muthén 2010). The overall fit indices met commonly accepted standards $\left(\chi^{2}(94)=342.22, p=.00\right.$; confirmatory fit index $[\mathrm{CFI}]=.98$; Tucker-Lewis index $[\mathrm{TLI}]=.97$; root mean square error of approximation $[\mathrm{RMSEA}]=.059$; probability of RMSEA $<.05=.01)$, so the measurement model provided a good fit for the data. Each construct revealed good psychometric properties in terms of composite reliability $(\mathrm{CR}>.91)$ and average variance extracted (AVE $>.76)$. The CR and AVE measures also indicated good internal consistency (see Tab. 1). We inspected the standardized loadings of the measures on the corresponding construct. The measures all exceeded a standardized loading of .70, in support of convergent validity. To evaluate discriminant validity, we used Fornell and Larcker's (1981) procedure. The root mean squared of the AVE of each factor was greater than its highest shared variance, and all items loaded higher on their associated construct than on other constructs. Thus, all constructs showed discriminant validity (see Tab. 2). To assess nonresponse bias, we compared the objective data associated with a group of community members who did not answer our questionnaire with data about respondents, but detected no significant differences in terms of member participation. 


\begin{tabular}{|c|c|c|c|c|c|c|c|c|c|c|}
\hline & 1 & 2 & 3 & 4 & 5 & 6 & 7 & 8 & 9 & 10 \\
\hline 1 Member's enjoyment & .90 & & & & & & & & & \\
\hline 2 Member's role clarity & .59 & .87 & & & & & & & & \\
\hline 3 Provider's responsiveness & .47 & .44 & .95 & & & & & & & \\
\hline 4 Co-members' cooperation & .58 & .42 & .53 & .88 & & & & & & \\
\hline 5 Community identification & .58 & .31 & .37 & .39 & .87 & & & & & \\
\hline 6 Member participation (initial level) & .19 & .26 & .17 & .06 & .12 & -- & & & & \\
\hline 7 Member participation (growth) & .08 & .07 & -.01 & -.01 & .01 & .22 & -- & & & \\
\hline 8 Community tenure & .00 & .00 & .00 & .00 & .00 & .33 & -.04 & -- & & \\
\hline 9 Age & .00 & .00 & .00 & .00 & .00 & .03 & -.04 & .03 & -- & \\
\hline 10 Gender & .00 & .00 & .00 & .00 & .00 & .08 & .04 & .00 & .02 & -- \\
\hline
\end{tabular}

Notes: Diagonal elements represent the root mean square value of the average variance extracted.

Tab. 2: Correlations of Main Constructs

\subsection{Hypotheses Testing}

Using latent growth curve modelling (LGCM), we analysed member participation over time and distinguished between the initial level and growth components. LGCM is an advanced application of structural equation modelling and analyses longitudinal changes (Eggert et al. 2014). Using measures observed across multiple time periods that capture the level of a variable, LGCM calculates the latent intercept (i.e. initial level) and latent slope (i.e. growth) of the developmental trajectory. Thus, researchers can describe longitudinal changes in the domain of interest (Chan 1998).

In our LGCM, the overall fit was good $\left(\chi^{2}=775.96\right.$, d.f. $=184, p=.000, \mathrm{CFI}=.97, \mathrm{TLI}=.96$, RMSEA $=.065, \mathrm{p}$-value $=.00$ ). The results of the LGCM are shown in Tab. 3. Interestingly, we found three types of drivers: outset drivers are those that have an effect on the initial level, but have no effect on growth (provider's responsiveness and community identification); loyalty drivers have no effect on the initial level, but do have an effect on growth (enjoyment); and comprehensive drivers have an effect on both (role clarity and co-members' cooperation, the latter albeit with a negative effect as a comprehensive inhibitor). 


\begin{tabular}{lcll}
\hline \multicolumn{1}{c}{ Path Tested } & $\begin{array}{c}\text { Standardized } \\
\text { Path Coefficient } \boldsymbol{\beta} \\
\text { Initial }\end{array}$ & \multicolumn{1}{c}{ Effects } & \multicolumn{1}{c}{ Type of Driver } \\
& Level/Growth & & \\
\hline H1a,b: Member's enjoyment $\rightarrow \mathrm{MP}$ & $.028^{\mathrm{ns}} / .081^{*}$ & no level, but growth effect & Loyalty driver \\
H2a,b: Member's role clarity $\rightarrow \mathrm{MP}$ & $.234^{* *} / .055^{*}$ & level \& growth effect & Comprehensive driver \\
H3a,b: Community identification $\rightarrow \mathrm{MP}$ & $.101^{* *} / .034^{\text {ns }}$ & level, but no growth effect & Outset driver \\
H4a,b: Co-members' cooperation $\rightarrow \mathrm{MP}$ & $-.148^{* *} / . .068^{*}$ & level \& growth effect & Comprehensive inhibitor \\
H5a,b: Provider's responsiveness $\rightarrow \mathrm{MP}$ & $.103^{* *} / . .037^{\text {ns }}$ & level, but no growth effect & Outset driver \\
\hline Notes: MP = income-generating member participation. Controls: community tenure, gender, age, ${ }^{*} p<.05 .,{ }^{* *} p<.01 .$, ns $=$ not \\
significant
\end{tabular}

Tab. 3: Latent Growth Model: Drivers of Member Participation

Based on the results of the LGCM estimation, $\mathrm{H}_{2 \mathrm{a}}, \mathrm{H}_{3 \mathrm{a}}$, and $\mathrm{H}_{5 \mathrm{a}}$ have been supported, whereas we did not find support for $\mathrm{H}_{1 \mathrm{a}}$ and $\mathrm{H}_{4}$, having predicted a positive rather than a negative effect for the latter. Furthermore, our data supports $\mathrm{H}_{1 b}$ and $\mathrm{H}_{2 \mathrm{~b}}$, but does not support $\mathrm{H}_{3 b}, \mathrm{H}_{4 b}$, and $\mathrm{H}_{5 b}$. Even though $\mathrm{H}_{4 b}$ was significant, we need to reject the hypothesis, because we predicted a positive and not a negative effect. We will discuss these results in the following section.

\section{Discussion and Implications}

\subsection{Discussion}

Our study expands earlier research on drivers of member participation in a trading community (Sichtmann et al., 2011), with a focus on the change of behaviour over time. Our data allowed us to investigate their effect on the initial level of members' participation as well as their effect on growth, i.e. increasing member participation in subsequent periods. We are thereby enhancing knowledge about the developmental trajectory of member participation in trading communities. This is important because trading communities rely on member participation for their long-term survival and as an important income generator (Cho and Menor 2010; Tsai and Bagozzi 2014; Zeng and Glaister 2016). We propose and test a conceptual model - rooted in earlier research (Sichtmann et al. 2011; Benoit et al. 2016), social exchange theory, and 
participation literature - which examines drivers of member participation related to all three actors in trades: the focal member, co-members, and the community provider (Benoit et al. 2017; de Valck et al. 2007). The results reveal three types of drivers, which we term outset drivers (only effective on the initial level), loyalty drivers (only effective on growth), and comprehensive drivers (effective on both). Thus, our findings provide trading community providers with a deeper understanding of what influences members to participate over time and how best to support members - and, with this information, enable them to sustain the community and generate income.

Before we consider the implications for theory and practice, three findings deserve further attention and discussion: 1) the negative relationship between co-member cooperation and member participation - what might be considered as the dark side of cooperation; 2) the fact that not all drivers have shown to be comprehensive, i.e. showing an effect on the initial level and the growth; and 3) the absence of an effect of enjoyment on the initial level of member participation.

First, in contrast with our H4, co-members' cooperation negatively influences member participation. This finding conflicts with research that emphasizes the importance of social components in online communities (Dholakia et al. 2009; Mathwick et al. 2008), but supports earlier and recent findings in the context of an information-based community (Benoit et al. 2016). Our data indicates that if other community members behave very cooperatively, focal members are discouraged from participating in the trading community. We think that cooperation operationalized as fairness, speed, and flexibility of co-members (see Tab. 2) might be perceived as elevated levels of these peers' professionalism, which is very common outside the collaborative consumption world. Thus, co-member cooperation in a peer-to-peer trading community might backfire in such a way that it 'kills' the atmosphere of the peer-to-peer trading 
community of initially non-professional members. For example, if a focal member has traded with a co-member who has sent the items on the same day or attaches many legal regulations to the trade or the exchange to express their fairness, the focal member might feel the pressure to behave similarly, which in itself might reduce participation. This member might even fear suffering reputational losses or receiving mediocre evaluations from co-members if he/she does not behave that 'cooperatively'.

Consider the example of eBay, which initially was mainly a community for non-commercial members who bought used products offered by other non-commercial members. Yet even though eBay continues to use the term 'member' on its website (see www.ebay.co.uk), a very high share of trades involves commercial providers, which suggests that eBay has in fact become a professional e-commerce site (like Amazon) rather than a community of like-minded members that sometimes offer and sometimes buy products in the community.

Taken together, the different atmosphere within the more 'professional' trading community might be a reason for the negative effect of co-members' cooperation. This would mean that a trading community can become 'too cooperative and too professional'. Overall, this interesting result challenges established opinions and former research (e.g. Dholakia et al. 2009; Mathwick et al. 2008), but it suggests that co-member cooperativeness might have a dark side.

Second, we assumed that all drivers would have an impact on the initial level and on growth, and as such would be comprehensive, which is not the case. Contrary to our assumptions, we found three different types of drivers: outset drivers, loyalty drivers, and comprehensive drivers. Hence, our results underscore the importance of distinguishing between the initial level and growth. In sum, the results show interesting dynamics in the developmental trajectory of member participation. 
Third, remarkably, a member's enjoyment has no effect on the initial level of participation, but over time affects its growth. Our interpretation is that trading communities are considered alternative consumption channels to e-commerce platforms, high-street stores, and flea markets. Enjoying trading will not instantly lead to more demand for the products offered there, but it will lead to a consideration of trading communities as an alternative channel to satisfy one's demand over time. Therefore, we have termed this as loyalty driver.

\subsection{Theoretical Contributions}

We contribute to participation literature in several ways since to the best of our knowledge, this is the first study that investigated participation in a trading community over time. First, the type of data that we were able to obtain reveals interesting immediate and sustained dynamics. Thus, our research responds to increasing calls for longitudinal study designs in the context of participation (Gallan et al. 2013; Guo et al. 2013; Yim et al. 2012). Our results show that it is important to differentiate between the initial level and the growth so that we also encourage other researchers to try to obtain longitudinal data to be able to investigate drivers in a more comprehensive and useful way.

Second, the negative effect of co-member cooperation on member participation indicates that too much cooperation - possibly perceived as professionalism by non-professional members - has a dark side. In general, we believe that academia focuses too much on the positive outcomes of variables rather than investigating their dark, inhibiting sides. Thus, we contribute to this stream of research and encourage more research in this area, such as that done by Heidenreich et al. (2015).

Third, in building our model of drivers of member participation, we consider factors that are key to customer participation (e.g. Auh et al. 2007; Meuter et al. 2005). Thus, we transfer the 
insights of customer participation literature to a trading community - a transfer that surprisingly has not previously been attempted. Applying these insights offers a far more detailed picture of possible drivers of member participation. In particular, a member's role clarity and the provider's responsiveness exert significant influence on actual community members' behaviour. These effects have been analysed previously in an information-based context (Benoit et al. 2016), but not in a trading community context.

Fourth, our empirical data allows us to test our hypothesis using the actual behaviour of trading community members. This approach prevents some biases that are related to selfreporting, e.g. over/underreporting (Donaldson and Grant-Vallone 2002) or relying on one type of data only, e.g. common method bias (Podsakoff et al. 2003). Thus, our results are more managerially relevant because they provide crucial insights into how to make members more active and ultimately generate more income, which is especially challenging in competitive online environments.

\subsection{Managerial Implications}

Our results have various implications for trading community providers. Given its immediate level and lasting growth effect, enhancing role clarity is the most effective and sustainable driver of member participation in trading communities. Role clarity, conceptualized as communityspecific knowledge, can for example be influenced by 1) creating an easy-to-use community with stability in its features; 2) showcasing successful trades, e.g. through member classification; 3) establishing supporting mechanisms; and 4) lowering entry barriers for members to enhance role clarity by 'trial and error'. In what follows, we give examples - inspired by the managerial world - of how to implement these activities. 
Creating an easy-to-use community to enhance role clarity can be done by describing and explaining the service process or by granting help when members cannot make use of a specific community tool. One community that focuses on the ease of trading is Totspot, a trading community for predominantly children's clothes that claims: "Sell in 45 seconds, selling is as easy as a breeze" (www.totspot.me/sell). Ease of use is particularly important in trading communities, especially when it seems that online community providers often change or enhance features to offer something new to enhance excitement and enjoyment. In trading communities, this should be done carefully and not at the expense of role clarity, since investments in role clarity will have higher leverage than those aiming to enhance enjoyment. Our finding also underlines the more goal-oriented nature of trading communities.

Providers might also consider showcasing successful trades to enhance role clarity through short educational videos - as done by BoxCycle, a trading community for used moving or storage boxes (www.boxcycle.com). Furthermore, community providers might consider classifying the member base according to their experience (e.g. eBay power sellers).

Distinguishing between expert/premium members and novices increases transparency such that it becomes clear which members likely know the unwritten rules of the trading community (Tsai and Bagozzi 2014) and might serve as models for less experienced members.

Establishing support mechanisms within the community also proves useful in enhancing role clarity. There are multiple mechanisms that trading community providers could offer: a) a personal support hotline for employees to give members support; b) avatars or other electronic support functions (e.g. IKEA’s Anna); or c) a mentoring program among different members within the community. The last may be an effective way to deliver this support via the 
community, but also bears the risk of varying quality and low cohesiveness (Boudreau and Lakhani 2013).

Totspot even offers a concierge service, meaning that members can simply send a bag of their children's clothes so that the concierge can handle the trade (see www.totspot.me/concierge). Even though this service does not enhance the role clarity of the focal member, it certainly reduces the effect that a perception of lacking role clarity has on inhibiting member participation.

With regard to the fourth point, lowering entry barriers for members to enhance role clarity by 'trial and error' in a trading community - 'learning by doing', which is very powerful (Arrow 1962) - is not feasible without resulting in an actual trade with a co-member. Thus, the barriers to enhancing role clarity through learning by doing are quite high. One possible way to lower those perceived barriers for new members to participate in trading is by, after a successful trade, granting a defined period of time (e.g. one hour or one day) to reverse it. This would be similar to airlines that allow changes to bookings at no charge (e.g. British Airways) within a day after the booking to reduce the uncertainty of the booking process.

Second, in line with the literature on online consumer behaviour, we assume that hedonic aspects such as social benefits (Dholakia et al. 2009) substantially drive member participation. Yet enjoyment showed no effect on the initial level of member participation, only on its growth over time; thus, enjoyment may be categorized as a loyalty driver. Our interpretation is that a member who enjoys trading will not have more demand for products just because they enjoy the activity, but they will show growth over time because they choose the trading community over other channels whenever they do have a demand. This is important for providers of trading 
communities to recognize, because even though enjoyment has no immediate effect on the participation level, it has a lasting one that stabilizes the ongoing activity of the member base.

Third, it is interesting that provider responsiveness is 'only' an outset driver, and thus has immediate effects on the initial participation level but none on growth. With respect to communities of interest and the interactions between the provider and the entire member base, de Valck et al. (2007) have found a similar effect, in that improvements in communication are best made at the beginning of the relationship for such interactions to be effective, but the effect weakens over time. Provider presence or responsiveness might be a necessary condition to stimulate the initial level of participation; however, when members are aware that the provider deals with problems or incidents, it will not enhance activity over time.

Fourth, we have discussed the negative effect of co-member cooperation on focal member participation - an effect that seems to contradict prior literature (e.g. Dholakia et al. 2009; Mathwick et al. 2008), but that has been found in an online community setting before (Benoit et al. 2016). We suggest that too much cooperation, possibly perceived as professionalism by nonprofessional members, might ' $k$ ill' the initial atmosphere of the trading community as a platform for peer-to-peer sharing, and as such backfires by decreasing member participation. For example, if a book lover has joined the trading community BookMooch to exchange books with comembers and finds himself/herself frequently being offered books by very cooperative (i.e. professional) bookstores that are extremely quick and flexible, the experience might then more resemble an e-commerce platform rather than an online community - a development that partly happened to eBay. If this holds, trading providers should be aware that allowing commercial members to participate in their community might have a downside, insofar as it negatively impacts the participation of the existing (non-commercial) member base. 
In line with prior research relating to online communities in general, we included community identification (Bagozzi and Dholakia 2006) in our model. Interestingly, we can show that it has an effect on the initial level of participation, but not on growth; we describe it as an outset driver. Thus, in keeping with the rather goal-oriented and functional nature of the trading community, identification influences the level, but does not increase participation over time. Our results show no support for a claim we found on BookMooch that "people join BookMooch for the books; they stay for the community". According to our results, people join and show initial participation because they can identify with the idea of the community, but they stay because they enjoy trading books. The platform Stuffstr is more aligned with our results by preventing potential new members from signing up for the trading community without a prior invitation (see www.stuffstr.com), emphasizing the community.

Overall, when a trading community provider aims to increase member participation, it should consider all three groups of stakeholders relevant in collaborative consumption: the focal member, co-members, and the community provider himself/herself (Benoit et al. 2016; Benoit et al. 2017; de Valck et al. 2007). For example, if they neglect the effects of co-members or the structure of the member base, the provider cannot address the possible dark side of co-member behaviour. We further conclude that the recommendations for enhancing member participation that relate to information-based communities (e.g. Facebook and LinkedIn) can only be transferred to trading communities with caution (see e.g. community identification). Lastly, trading community providers should be aware that drivers could be outset or loyalty drivers and only have an effect on a certain period of time. Thus, individual drivers should not be neglected because they seem to have no (instant level or long-term growth) effect. Only role clarity has proven to be a comprehensive driver. 


\section{Limitations and Further Research}

Every research design is subject to limitations that must be kept in mind when considering our results and implications. First of all, our data was collected in a trading community focused on media in one particular country; therefore, it potentially has a limited scope. We thus encourage more research on trading communities in different contexts and countries. Furthermore, we deduced the most important drivers of participation from various streams of literature, which means that we might have missed some drivers that are perceived as relevant in other contexts. Another limitation is that our model only investigates main effects, albeit on two different dependent variables; further research could thus investigate boundary conditions. Our aim was to gain initial insights into the drivers of member participation. Even though in the Managerial Implications section we recommend some instruments that could enhance the drivers, e.g. to enhance role clarity by showcasing successful trades, it was not our intent to develop concrete means to investigate their implementation. Additional research should focus on the effectiveness of community-specific tools that increase role clarity.

In addition, some of the hypotheses that failed to receive support from our data suggest interesting avenues for further research. The negative effect of co-member cooperation, and thus the potential dark side of cooperation, requires more attention. Finally, there is more to learn about enjoyment as a 'loyalty driver' with no effect on the initial level of participation, as well as community identification as an 'outset driver' that has an instant level but not growth effect. We proposed some possible explanations above, but additional studies should further investigate those dynamics. 


\section{References}

Algesheimer, R., Dholakia, U. M., \& Herrmann, A. (2005). The Social Influence of Brand Community: Evidence from European Car Clubs, Journal of Marketing, 69 (3), 19-34.

Arena, R. \& Conein, B. (2008). On Virtual Communities: Individual Motivations, Reciprocity and We-rationality, International Review of Economics, 55 (1), 185-208.

Arrow, K. J. (1962). The Economic Implications of Learning by Doing, The Review of Economic Studies, 29 (3), $155-173$.

Auh, S., Bell, S. J., McLeod, C. S., \& Shih, E. (2007). Co-Production and Customer Loyalty in Financial Services, Journal of Retailing, 83 (3), 359-370.

Bagozzi, R. P. \& Dholakia, U. M. (2006). Open Source Software User Communities: A Study of Participation in Linux User Groups, Management Science, 52 (7), 1099-1115.

Bakos, Y. \& Katsamakas, E. (2008). Design and Ownership of Two-Sided Networks: Implications for Internet Platforms, Journal of Management Information Systems, 25 (3), 171-202.

Bendapudi, N. \& Leone, R. P. (2003). Psychological Implications of Customer Participation in Co-Production, Journal of Marketing, 67 (1), 14-28.

Benkenstein, M., Bruhn, M., Büttgen, M., Hipp, C., Matzner, M., \& Nerdinger, F.W. (2017). Topics for Service Management Research - A European Perspective, Journal of Service Management Research, 1 (1), 4-21.

Benoit, S., Bilstein, N., Hogreve, J., \& Sichtmann, C. (2016). Explaining social exchanges in information-based online communities (IBOC), Journal of Service Management, 27 (4), 460-480.

Benoit, S., Baker, T., Bolton, R., Gruber, T., \& Kandampully, J. (2017). A Triadic Framework for Collaborative Consumption: Motives, roles and resources, Journal of Business Research, 79, 219-227.

Bowen, D. E. (1986). Managing Customers as Human Resources in Service Organizations, Human Resource Management, 25 (3), 371-383.

Byrne, B. M., Lam, W. W., \& Fielding, R. (2008). Measuring Patterns of Change in Personality Assessments: An Annotated Application of Latent Growth Curve Modeling, Journal of Personality Assessment, 90 (6), 536-546.

Chan, D. (1998). The Conceptualization and Analysis of Change Over Time: An Integrative Approach Incorporating Longitudinal Mean and Covariance Structures Analysis (LMACS) and Multiple Indicator Latent Growth Modeling (MLGM), Organizational Research Methods, 1 (4), 421-483. 
Chan, K. W., Yim, C. K., \& Lam, S. S. K. (2010). Is Customer Participation in Value Creation a Double-Edged Sword? Evidence from Professional Financial Services Across Cultures, Journal of Marketing, 74 (3), 48-64.

Childers, T. L., Carr, C. L., Peck, J., \& Carson, S. (2001). Hedonic and Utilitarian Motivations for Online Retail Shopping Behavior, Journal of Retailing, 77 (4), 511-535.

Cho, Y. K. \& Menor, L. J. (2010). Toward a Provider-Based View on the Design and Delivery of Quality E-Service Encounters, Journal of Service Research, 13 (1), 83-95.

Dabholkar, P. A. \& Bagozzi, R. P. (2002). An Attitudinal Model of Technology-Based Self-Service: Moderating Effects of Consumer Traits and Situational Factors, Journal of the Academy of Marketing Science, 30 (1), 184201.

De Valck, K., Langerak, F., Verhoef, P. C., \& Verlegh, P. W. J. (2007). Satisfaction with Virtual Communities of Interest: Effect on Members' Visit Frequency, British Journal of Management, 18 (3), 241-256.

Dholakia, U. M., Blazevic, V., Wiertz, C., \& Algesheimer, R. (2009). Communal Service Delivery: How Customers Benefit From Participation in Firm-Hosted Virtual P3 Communities, Journal of Service Research, 12 (2), 208226.

Donaldson, S. I. \& Grant-Vallone, E. J. (2002). Understanding Self-Report Bias: In Organizational Behavior Research, Journal of Business and Psychology, 17 (2), 245-260.

Eggert, A., Hogreve, J., Ulaga, W., \& Münkhoff, E. (2014). Revenue and Profit Implications of Industrial Service Strategies, Journal of Service Research, 17 (1), 23-39.

Etgar, M. (2008). A Descriptive Model of the Consumer Co-Production Process: Journal of the Academy of Marketing Science, 36, 97-108.

Fornell, C. \& Larcker, D. F. (1981). Evaluating Structural Equation Models with Unobservable Variables and Measurement Error, Journal of Marketing Research, 18 (1), 39-50.

Frow, P., Nenonen, S., Payne, A., \& Storbacka, K. (2015). Managing Co-creation Design: A Strategic Approach to Innovation, British Journal of Management, 26 (3), 463-483.

Füller, J., Mühlbacher, H., Matzler, K., \& Jawecki, G. (2009/10). Consumer Empowerment Through Internet-based Co-creation, Journal of Management Information Systems, 26 (3), 71-102.

Gallan, A. S., Jarvis, C. B., Brown, S. W., \& Bitner, M. J. (2013). Customer Positivity and Participation in Services: An Empirical Test in a Health Care Context, Journal of the Academy of Marketing Science, 41 (3), 338-356. 
Groth, M. (2005). Customers as Good Soldiers: Examining Citizenship Behaviors in Internet Service Deliveries, Journal of Management, 31 (2), 7-27.

Guo, L., Arnould, E. J., Gruen, T. W., \& Tang, C. (2013). Socializing to Co-Produce: Pathways to Consumers' Financial Well-Being, Journal of Service Research, 16 (4), 549-563.

Hamari, J., Sjöklint, M., \& Ukkonen, A. (2016). The sharing economy: Why people participate in collaborative consumption, Journal of the Association for Information Science and Technology, 67 (9), 2047-2059.

Heidenreich, S., Wittkowski, K., Handrich, M., \& Falk, T. (2015). The dark side of customer co-creation: exploring the consequences of failed co-created services, Journal of the Academy of Marketing Science, 43 (3), 279-296.

Homburg, C. \& Fürst, A. (2005). How Organizational Complaint Handling Drives Customer Loyalty: An Analysis of the Mechanistic and the Organic Approach, Journal of Marketing, 69 (3), 95-114.

Koh, J., Young-Gul, K., Butler, B., \&. Bock, G-W. (2007). Encouraging Participation in Virtual Communities, Communications of the ACM, 50, February, 69-73.

Köhler, C. F., Rohm, A. J., de Ruyter, K., \& Wetzels, M. (2011). Return on Interactivity: The Impact of Online Agents on Newcomer Adjustment, Journal of Marketing, 75 (1), 93-108.

Kozinets, R. V., de Valck, K., Wojnicki, A. C., \& Wilner, S. J. S. (2010). Networked Narratives: Understanding Word-of-Mouth Marketing in Online Communities, Journal of Marketing, 74 (2), 71-89.

Lengnick-Hall, C. A. (1996). Customer Contributions to Quality: A Different View of the Customer-Oriented Firm, Academy of Management Review, 21 (3), 791-824.

Lusch, R. F., Vargo, S. L., \& O’Brien, M. (2007). Competing Through Service: Insights from Service-Dominant Logic, Journal of Retailing, 83 (1), 5-18.

Mathwick, C., Wiertz, C., \& de Ruyter, K. (2008). Social Capital Production in a Virtual P3 Community, Journal of Consumer Research, 34, 6, 832-849.

Matzner, M., Büttgen, M., Demirkan, H., Spohrer, J., Alter, S., Fritzsche, A., Ng, I. C. L., Jonas, J. M., Martinez, V., Möslein, K. M., \& Neely, A. (2018). Digital Transformation in Service Management, Journal of Service Management Research, 2 (2), 3-21.

Meuter, M. L., Bitner, M. J., Ostrom, A. L., \& Brown, S. W. (2005). Choosing Among Alternative Service Delivery Modes: An Investigation of Customer Trial of Self-Service Technologies, Journal of Marketing, 69 (2), 61-83. Muthén, L. K. \& Muthén, B. O. (2010). Mplus User's Guide, Los Angeles, Muthén \& Muthén. 
Nonnecke, B., Andrews, D., \& Preece, J. (2006). Non-Public and Public Online Community Participation: Needs, Attitudes and Behavior, Electronic Commerce Research, 6 (1), 7-20.

Parker, G. G. \& Van Alstyne, M. W. (2005). Two-Sided Network Effects: A Theory of Information Product Design, Management Science, 51 (10), 1494-1504.

Ployhart, R. E. \& Vandenberg, R. J. (2010). Longitudinal Research: The Theory, Design and Analysis of Change, Journal of Management, 36 (1), 94-120.

Podsakoff, P. M., MacKenzie, S. B., Lee, J-Y., \& Podsakoff, N. P. (2003). Common method biases in behavioral research: A critical review of the literature and recommended remedies, Journal of Applied Psychology, 88 (5), 879-903.

Porter, C. E. \& Donthu, N. (2008). Cultivating Trust and Harvesting Value in Virtual Communities, Management Science, 54 (1), 113-128.

Ridings, C., Gefen, D., \& Arinze, B. (2006). Psychological Barriers: Lurker and Poster Motivation and Behavior in Online Communities, Communications of AIS, 18, 329-354.

Rothaermel, F. T. \& Sugiyama, S. (2001). Virtual Internet Communities and Commercial Success: Individual and Community-Level Theory Grounded in the Atypical Case of TimeZone.com, Journal of Management, 27 (3), $297-312$.

Scarpi, D. (2010). Does Size Matter? An Examination of Small and Large Web-Based Brand Communities, Journal of Interactive Marketing, 24, 14-21.

Troye, S. V. \& Supphellen, M. (2012). Consumer Participation in Customer Participation: 'I Made It Myself' Effects on Consumers' Sensory Perceptions and Evaluations of Outcome and Input Product, Journal of Marketing, 76 (1), 33-46.

Tsai, H-T. \& Bagozzi, R. P. (2014). Contribution Behavior in Virtual Communities: Cognitive, Emotional and Social Influences, MIS Quarterly, 38 (1), 143-63.

Venkatesh, V., Speier, C., \& Morris, M. G. (2002). User Acceptance Enablers in Individual Decision Making About Technology: Toward an Integrated Model, Decision Sciences, 33 (1), 297-316.

Verleye, K. (2015). The co-creation experience from the customer perspective: its measurement and determinants, Journal of Service Management, 26 (2), 321-342.

Wiertz, C. \& de Ruyter, K. (2007). Beyond the Call of Duty: Why Customers Contribute to Firm-hosted 
Commercial Online Communities, Organization Studies, 28 (3), 347-376.

Yim, C. K., Chan, K. W., \& Lam, S. S. K. (2012). Do Customers and Employees Enjoy Service Participation? Synergistic Effects of Self- and Other-Efficacy, Journal of Marketing, 76 (4), 121-140.

Zeng, J. \& Glaister, K. (2016). Competitive dynamics between multinational enterprises and local internet platform companies in the virtual market in China, British Journal of Management, 27 (3), 479-496. 